Case Report

\title{
Higher Risk Myelodysplastic Syndromes in Patients with Well-Controlled HIV Infection: Clinical Features, Treatment, and Outcome
}

\author{
Bradley T. Williamson ${ }^{1}$ and Heather A. Leitch ${ }^{2}$ \\ ${ }^{1}$ Medicine, St. Paul's Hospital and the University of British Columbia, Vancouver, BC, Canada V6Z $2 A 5$ \\ ${ }^{2}$ Hematology, St. Paul's Hospital and the University of British Columbia, Vancouver, BC, Canada V6Z $2 A 5$
}

Correspondence should be addressed to Heather A. Leitch; hleitch@providencehematology.com

Received 7 October 2015; Accepted 27 December 2015

Academic Editor: Ramon Tiu

Copyright (C) 2016 B. T. Williamson and H. A. Leitch. This is an open access article distributed under the Creative Commons Attribution License, which permits unrestricted use, distribution, and reproduction in any medium, provided the original work is properly cited.

\begin{abstract}
Introduction. In advanced HIV prior to combination antiretroviral therapy (ART), dysplastic marrow changes occurred and resolved with ART. Few reports of myelodysplastic syndromes (MDS) in well-controlled HIV exist and management is undefined. Methods. Patients with well-controlled HIV and higher risk MDS were identified; characteristics, treatment, and outcomes were reviewed. Results. Of 292 MDS patients since 1996, 1 (0.3\%) was HIV-positive. A 56-year-old woman presented with cytopenias. CD4 was 1310 cells/mL and HIV viral load $<40$ copies/mL. Bone marrow biopsy showed RCMD and karyotype included del(5q) and del(7q); IPSS was intermediate- 2 risk. She received azacitidine at 75\% dose. Cycle 2, at full dose, was complicated by marrow aplasia and possible AML; she elected palliation. Three additional HIV patients with higher risk MDS, aged 56-64, were identified from the literature. All had deletions involving chromosomes 5 and 7. MDS treatment of 2 was not reported and one received palliation; all died of AML. Conclusion. Four higher risk MDS in well-controlled HIV were below the median age of diagnosis for HIV-negative patients; all had adverse karyotype. This is the first report of an HIV patient receiving MDS treatment with azacitidine. Cytopenias were profound and dosing in HIV patients should be considered with caution.
\end{abstract}

\section{Introduction}

The myelodysplastic syndromes (MDS) are clonal hematopoietic stem cell disorders characterized by ineffective hematopoiesis and risk of progression to acute myeloid leukemia (AML) $[1,2]$. The diagnosis of MDS is made according to World Health Organization (WHO) [3] criteria and prognosis determined by the International Prognostic Scoring System (IPSS) [4] and other scores. MDS is thought to result from mutations in the pluripotent stem cell $[5,6]$, resulting in dysplasia and ineffective hematopoiesis. Mutations in genes coding the RNA splicing machinery [7], haploinsufficiency of ribosomal proteins [8], telomere disruption [9], abnormal microRNA expression [10], aberrant DNA methylation patterns [11], and immune dysregulation $[12,13]$ may play a role in MDS pathogenesis.

The relationship between MDS and the immune system is poorly understood; however, cytokine dysregulation $[14,15]$ and impaired cellular immunity $[16,17]$ have been implicated in MDS initiation, development, and progression. Autoimmune manifestations (AIM) may occur in up to $30 \%$ of MDS patients $[18,19]$ and may be associated with MDS onset at a younger age and adverse cytogenetics [19-21]. Patients with immune disorders and/or receiving immunosuppressive medications are more likely to be diagnosed with MDS or AML $[22,23]$, and paraneoplastic inflammatory syndromes may occur concomitant with MDS diagnosis [20,24-27].

The protease inhibitors became available for the treatment of HIV infection in 1996, introducing the era of combination antiretroviral therapy (ART). For patients with advanced HIV infection in the pre-ART era, dysplastic marrow changes were a frequent finding and these resolved with antiretroviral treatment $[28,29]$. There are few reports of MDS in well-controlled HIV infection [30-32] and an approach to management is largely undefined. Here, we describe the characteristics and clinical course of a patient 
presenting with higher IPSS risk MDS in the setting of wellcontrolled HIV infection and compare to the features of three patients reported in the literature. We discuss the effect of immune dysregulation on the development of MDS, the possible role of HIV and/or ART in MDS development, and treatment of our patient with azacitidine.

\section{Methods}

Patients with MDS in well-controlled HIV infection were identified from the MDS clinical database and the literature and reviewed for MDS and HIV clinical and laboratory characteristics, treatment, and outcome.

This review was conducted in accordance with the requirements of the Institutional Research Ethics Board.

\section{Results}

A 56-year-old woman with a longstanding history of HIV infection, well-controlled on ART, was referred with fatigue and cytopenias. Eastern Cooperative Oncology Group (ECOG) performance status (PS) was 1 [33]. On atazanavir, emtricitabine, and tenofovir, the CD 4 count was 1310 cells $/ \mathrm{mL}$ with a CD4 fraction of $29 \%$ and HIV viral load (VL) was undetectable at $<40$ copies $/ \mathrm{mL}$. Sequential complete blood count with differential revealed a white blood cell (WBC) count of $11.3 \times 10^{9} / \mathrm{L}$, neutrophils fluctuating between $0.18 \times$ $10^{9} / \mathrm{L}$ and $1.9 \times 10^{9} / \mathrm{L}$, hemoglobin $(\mathrm{Hb})$ of $75 \mathrm{~g} / \mathrm{L}$, and platelet count (PLTS) of $132 \times 10^{9} / \mathrm{L}$. Morphology review revealed giant platelet forms and pelgeroid changes. A bone marrow aspirate and biopsy (BMBx) showed a hypercellular marrow (100\% cellularity) with trilineage dysplasia, $4 \%$ blasts, and cytogenetic analysis revealed a complex karyotype including deletion of $5 q$ and $7 q$, a dicentric chromosome $(9 ; 12)$ with break points at $9 \mathrm{q}$ and $12 \mathrm{p}$, a marker chromosome, a ring chromosome, and two tetraploid metaphases. A diagnosis of refractory cytopenia with multilineage dysplasia (RCMD) was made and the IPSS score was intermediate- 2 risk.

While awaiting cytogenetic analysis to determine IPSS risk, she presented with high fevers, drenching sweats, rigors, and chills. A chest X-ray showed pulmonary infiltrates. ECOG PS was 3. She was admitted to hospital and an extensive workup including bronchoscopy and repeat BMBx revealed no infectious cause and no sign of MDS progression. The symptoms resolved spontaneously over the following four weeks.

She received transfusion support and two cycles of azacitidine, with a plan to bridge to allogeneic hematopoietic stem cell transplantation; the antiretroviral regimen was continued unchanged throughout. The first azacitidine cycle was given at a dose reduction of $25 \%$ due to uncertainty as to how it would be tolerated in the setting of HIV and ART. Throughout this cycle, the patient was clinically very well with an ECOG PS of 0 . The nadir counts of five intervening measurements were neutrophils 0.1, hemoglobin 75, and platelets 13. She received transfusion of 2 units of packed red blood cells and one pack of platelets. The second cycle of azacitidine was given at $100 \%$ dose and was complicated by prolonged and profound cytopenias lasting over four weeks (neutrophils $0.1 \times 10^{9} / \mathrm{L}$, transfused $\mathrm{Hb} 83 \mathrm{~g} / \mathrm{L}$, and transfused PLTS $2 \times 10^{9} / \mathrm{L}$ ) and Pseudomonas bacteremia. Aspergillus infection and atypical mycobacterial infection were suspected but not proven. A third BMBx showed aplasia and possible progression to acute erythroleukemia. The patient elected comfort care and died. See Figure 1 for a summary of the patient's course.

There are three other cases in the literature of patients with reasonable HIV control on ART (CD4 > 200 cells $/ \mathrm{mL}$ with negative HIV VL, $n=2$; and CD4 > 500 with VL uncertain, $n=1$ ) presenting with MDS that is clearly reported to be higher IPSS risk (see Table 1) [30, 32]. At ages 56,60 , and 63 , like our patient, all were below the median age of MDS diagnosis in the HIV-negative population. All four patients had a complex karyotype including deletions involving chromosomes 5 and 7. The marrow blast count was not reported in the first 2 patients and was $12 \%$ in the third. Treatment for MDS received by two patients was not reported and the third received supportive care; all died of AML progression within three to six months of MDS diagnosis.

\section{Discussion}

Dysplastic changes to the marrow were a common finding in advanced HIV infection prior to the advent of protease inhibitors and ART [28, 29], and these generally resolved with the institution of effective HIV treatment. Our patient with higher risk MDS had a longstanding history of HIV infection which was well controlled with ART. Other reports have recently emerged [30-32] describing patients presenting with MDS in well-controlled HIV, suggesting that HIV-positive patients are now living long enough to develop age-related conditions such as MDS.

Several reports have documented an association between AIM and MDS [20, 24-27]. Acute systemic vasculitis may present as culture negative fever and pulmonary infiltrates, which our patient exhibited, and an autoimmune cause was suspected though not conclusively demonstrated [20, 34]. Some inflammatory syndromes may precede the diagnosis of MDS [23], suggesting a role in MDS development and progression and raising the possibility that residual immune dysregulation in treated HIV may contribute to MDS development. Immune dysregulation in MDS includes abnormal levels and activity of tumor necrosis factor alpha (TNF- $\alpha$ ), transforming growth factor beta (TGF- $\beta$ ) [35], interferon- (IFN-) $\gamma$, and interleukin- (IL-) 6 [14]. TNF- $\alpha$ facilitates apoptosis of CD34-positive cells [36] and results in upregulation of proinflammatory cytokines [37], leading to decreased B-cell proliferation and natural killer (NK) cell dysfunction. Deletions and mutations in the tumor suppressor interferon regulatory factor-1 (IRF-1) gene, as well as alternative splicing of IRF-1 mRNA, have been found in MDS $[38,39]$. Aberrant activity of the immune regulatory $\gamma \delta$ T cells (CD8+) has been shown $[36,40]$. In higher risk MDS, NK cell levels are decreased, and regulatory T cells (also CD8+) are increased $[41,42]$, both presumably leading to aberrant immune surveillance and MDS progression [43-46]. Thus, many levels of immune dysregulation may contribute to the development of MDS. It is possible that some or all of this 


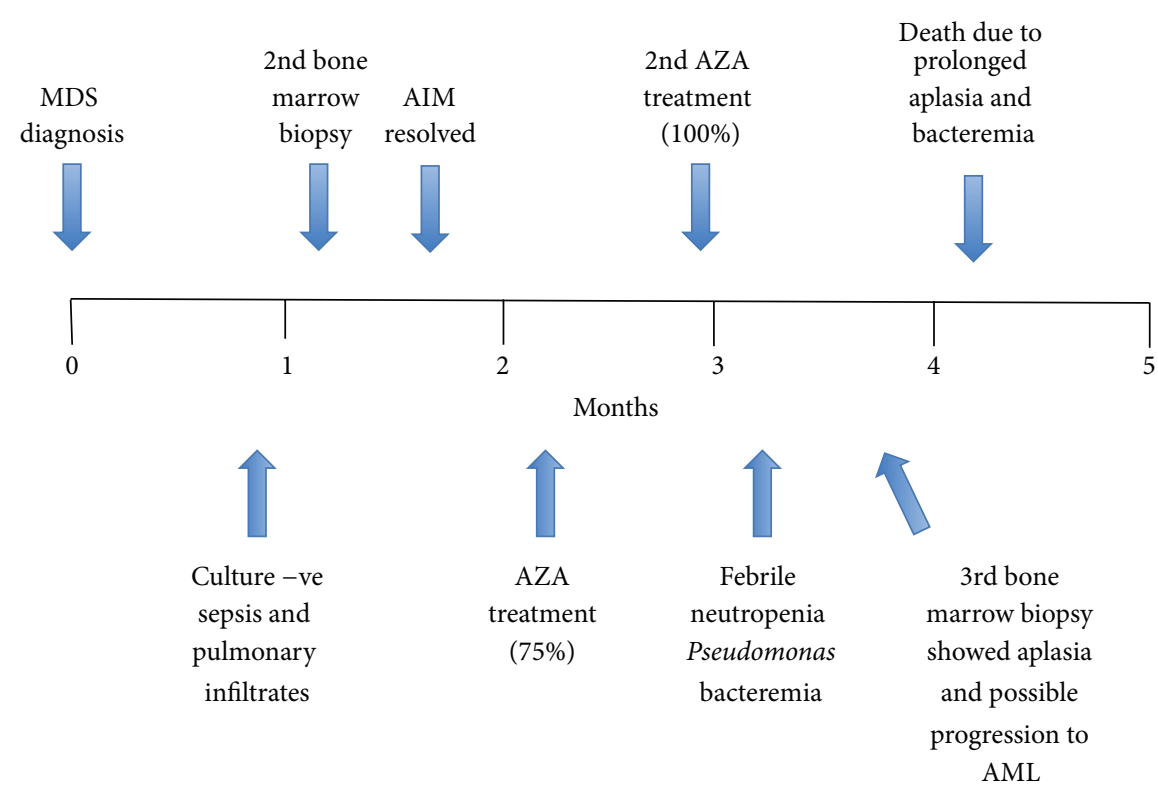

FIGURE 1: Clinical course of a patient presenting with higher IPSS risk MDS in the context of well-controlled HIV infection. AIM: autoimmune manifestations; AML: acute myeloid leukemia; AZA: azacitidine; IPSS: International Prognostic Scoring System; MDS: myelodysplastic syndrome.

immune dysregulation may differ in extent or frequency in HIV-positive patients. Though information on cytokine levels in ART treated patients is incomplete and sometimes conflicting, TNF- $\alpha$, IFN- $\gamma$, IL- 6 , and T regulatory cells have been reported to be increased [47-50] and one study shows an association between increased CD8 cell numbers and decreased NK cell function [51]. While our patient's CD4 count was well preserved at 1,310 cells/mL, the CD 4 fraction was only $29 \%$, indicating a CD8 count of 4517 cells $/ \mathrm{mL}$. We do not have information on this patient's CD8 subtypes but speculate that her high CD8 count may have allowed AIM, and possibly MDS, development. There are similar reports of an association between AIM in MDS and infection with the HIV-related retrovirus human T lymphotropic virus-1 (HTLV-1) [52].

The prognostic impact of the presence of AIM in MDS is unclear $[20,21]$. Immunosuppressive medications such as prednisone, cyclophosphamide, and azathioprine have been used [20, 53-55]; however, remissions are not sustained. Paraneoplastic AIM may respond to azacitidine, which may have immunomodulatory effects such as reduction of immunemediated cytotoxicity and increased IFN-gamma production $[25,56]$.

Our patient and the three other patients with higher IPSS risk MDS and well-controlled HIV infection reported in the literature all had a complex karyotype, and all had deletions involving both chromosomes 5 and 7 . The significance of this finding is uncertain; however, both abnormalities of these particular chromosomes and complex cytogenetic abnormalities are common in therapy-related MDS [57]. Some data suggest that protease inhibitors may decrease cellular efflux of toxins, and it is possible that this may contribute to the development of MDS in general and specific chromosomal abnormalities in particular [58]. Similarly, while azacitidine is not metabolized by the hepatic cytochrome P450 system and would not be expected to interact directly with antiretroviral medications, it is possible that increased cytotoxicity could result from decreased cellular efflux of this agent. Equally possible, however, is that marrow suppression from ART may be additive to marrow suppression from azacitidine; one study in NHL showed more cytopenias with chemotherapy in conjunction with PI-based ART compared with PI-sparing regimens [59].

Reports from the pre-ART era indicate direct infection of hematopoietic progenitor cells and bone marrow stromal cells with HIV $[60,61]$, which could contribute to cytopenias by decreasing the cellularity of the marrow, though whether these phenomena occur in well-controlled HIV infection is unclear. Our patient's marrow was hypercellular, as was the marrow of case 3 ; the marrow cellularity of cases 1 and 2 was not reported. Of particular interest in this setting are reports of HIV inhibitory activity of azacitidine and related compounds in preclinical models [62-64]. It may prove in future that ARV regimens may be modified in patients receiving azacitidine or related compounds for MDS in HIV infection, though this approach should be considered investigational. Patients with well-controlled HIV and other hematological malignancies such as non-Hodgkin lymphoma (NHL) can currently be expected to have treatment outcomes equivalent to the HIV-negative population [65-68]. However, in HIV NHL patients, bone marrow function may be more borderline than in HIV-negative patients, for example, requiring more frequent use of cytokine support with chemotherapy [65]. Our patient was treated with azacitidine with the intent to induce remission and/or delay AML progression and bridge to allogeneic hematopoietic stem cell transplantation. While she tolerated the first cycle of azacitidine, given at a $25 \%$ dose reduction, well, the second cycle resulted in 


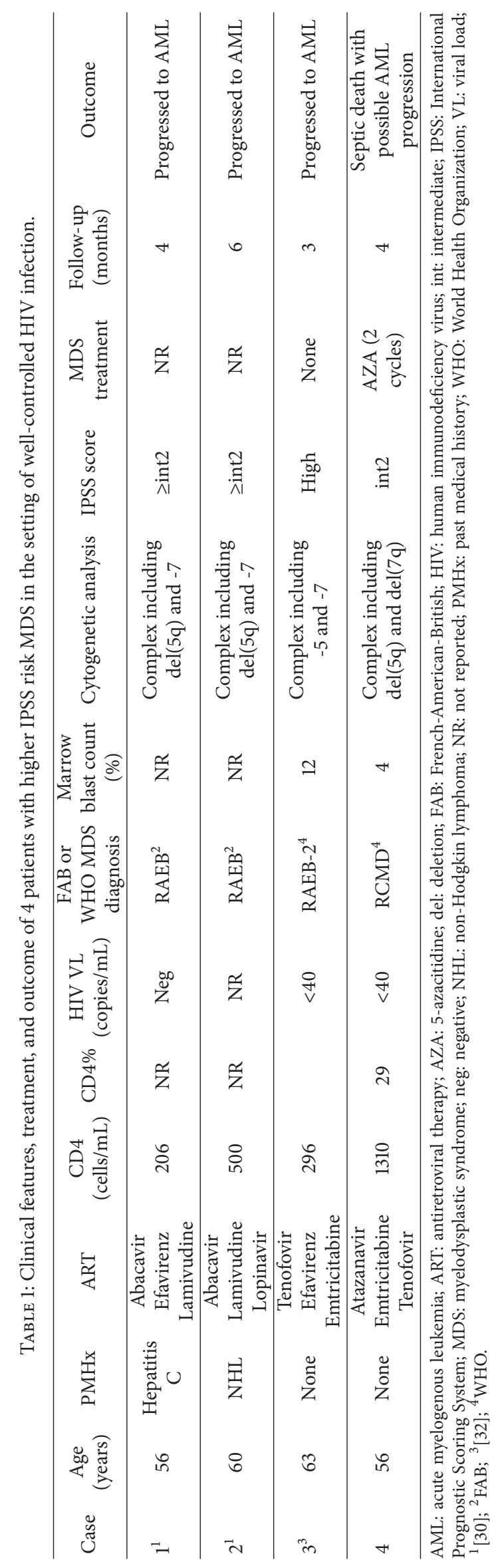


prolonged aplasia and serious infections. Guidelines suggest that dose reductions of azacitidine should be avoided if possible [69]; however, in HIV-positive patients with MDS, consideration of dose reductions may be prudent.

Finally, there are several reports of patients with MDS in HIV infection, including lower risk patients, who progressed rapidly (within 4-14 months) to AML following MDS diagnosis $[30,70,71]$. This suggests that the IPSS may, at least in some HIV-positive patients, underestimate the aggressiveness of the MDS and that these patients may be appropriate for vigilant monitoring and/or early intervention.

\section{Conclusion}

Of 292 MDS patients at our center in the ART era, one presented with higher IPSS risk MDS in well-controlled HIV infection, which may indicate that HIV-positive patients are currently living long enough to develop age-related complications such as MDS. This and three other reported patients with higher risk MDS in HIV were younger than HIV-negative MDS patients, and all patients had a complex karyotype and deletions involving chromosomes 5 and 7; this finding is of uncertain significance. To our knowledge, this is the first report of an HIV-positive patient receiving specific treatment for higher risk MDS with azacitidine. The patient died of sepsis with prolonged aplasia following azacitidine at $100 \%$ dose, which may indicate that, like HIV patients receiving ART and chemotherapy for lymphoma, cytopenias may be more profound than in HIV-negative patients, and dosing should be considered with caution. Our patient developed culture negative sepsis prior to MDS treatment, in keeping with reports of AIM leading to or presenting as a paraneoplastic manifestation of MDS. Whether AIM are more frequent in HIV-positive patients due to cellular and cytokine dysregulation is an unanswered question. MDS should remain on the differential diagnosis of patients with well-controlled HIV infection and cytopenias. These patients should be considered for the usual MDS therapies, though dose reductions with careful dose escalation as tolerated, should be considered.

\section{Conflict of Interests}

Bradley T. Williamson was supported by a summer studentship from Celgene Corporation. Heather A. Leitch has received honoraria and research funding from Celgene, Novartis, and Alexion and an educational grant from Celgene.

\section{References}

[1] L. Adès, R. Itzykson, and P. Fenaux, "Myelodysplastic syndromes," The Lancet, vol. 383, no. 9936, pp. 2239-2252, 2014.

[2] G. Garcia-Manero, "Myelodysplastic syndromes: 2014 update on diagnosis, risk-stratification, and management," American Journal of Hematology, vol. 89, no. 1, pp. 97-108, 2014.

[3] J. W. Vardiman, J. Thiele, D. A. Arber et al., "The 2008 revision of the World Health Organization (WHO) classification of myeloid neoplasms and acute leukemia: rationale and important changes," Blood, vol. 114, no. 5, pp. 937-951, 2009.

[4] P. Greenberg, C. Cox, M. M. LeBeau et al., "International scoring system for evaluating prognosis in myelodysplastic syndromes," Blood, vol. 89, no. 6, pp. 2079-2088, 1997.

[5] B. Will, L. Zhou, T. O. Vogler, S. Ben-Neriah, C. Schinke, R. Tamari et al., "Stem and progenitor cells in myelodysplastic syndromes show aberrant stage-specific expansion and harbor genetic and epigenetic alterations," Blood, vol. 120, no. 10, pp. 2076-2086, 2012, (Research Support, N.I.H., Extramural Research Support, Non-U.S. Gov't Research Support, U.S. Gov't, Non-P.H.S.).

[6] W. W. Pang, J. V. Pluvinage, E. A. Price et al., "Hematopoietic stem cell and progenitor cell mechanisms in myelodysplastic syndromes," Proceedings of the National Academy of Sciences of the United States of America, vol. 110, no. 8, pp. 3011-3016, 2013.

[7] K. Yoshida, M. Sanada, Y. Shiraishi, D. Nowak, Y. Nagata, R. Yamamoto et al., "Frequent pathway mutations of splicing machinery in myelodysplasia," Nature, vol. 478, no. 7367, pp. 64-69, 2011.

[8] B. L. Ebert, "Genetic deletions in AML and MDS," Best Practice and Research: Clinical Haematology, vol. 23, no. 4, pp. 457-461, 2010.

[9] M. Gadji, J. A. Awe, P. Rodrigues et al., "Profiling threedimensional nuclear telomeric architecture of myelodysplastic syndromes and acute myeloid leukemia defines patient subgroups," Clinical Cancer Research, vol. 18, no. 12, pp. 3293-3304, 2012.

[10] G. W. Rhyasen and D. T. Starczynowski, "Deregulation of microRNAs in myelodysplastic syndrome," Leukemia, vol. 26, no. 1, pp. 13-22, 2012.

[11] M. del Rey, K. O’Hagan, M. Dellett et al., “Genome-wide profiling of methylation identifies novel targets with aberrant hypermethylation and reduced expression in low-risk myelodysplastic syndromes," Leukemia, vol. 27, no. 3, pp. 610618, 2013.

[12] E. M. Sloand, C. O. Wu, P. Greenberg, N. Young, and J. Barrett, "Factors affecting response and survival in patients with myelodysplasia treated with immunosuppressive therapy," Journal of Clinical Oncology, vol. 26, no. 15, pp. 2505-2511, 2008.

[13] S. Y. Kordasti, B. Afzali, Z. Lim et al., "IL-17-producing $\mathrm{CD}^{+} \mathrm{T}$ cells, pro-inflammatory cytokines and apoptosis are increased in low risk myelodysplastic syndrome," British Journal of Haematology, vol. 145, no. 1, pp. 64-72, 2009.

[14] Y.-E. Claessens, D. Bouscary, J.-M. Dupont et al., "In vitro proliferation and differentiation of erythroid progenitors from patients with myelodysplastic syndromes: evidence for Fasdependent apoptosis," Blood, vol. 99, no. 5, pp. 1594-1601, 2002.

[15] W. Zeng, A. Miyazato, G. Chen, S. Kajigaya, N. S. Young, and J. P. Maciejewski, "Interferon-gamma-induced gene expression in CD34 cells: identification of pathologic cytokine-specific signature profiles," Blood, vol. 107, no. 1, pp. 167-175, 2006.

[16] E. M. Sloand, L. Mainwaring, M. Fuhrer et al., "Preferential suppression of trisomy 8 compared with normal hematopoietic cell growth by autologous lymphocytes in patients with trisomy 8 myelodysplastic syndrome," Blood, vol. 106, no. 3, pp. 841-851, 2005.

[17] E. M. Sloand, J. J. Melenhorst, Z. C. G. Tucker et al., "T-cell immune responses to Wilms tumor 1 protein in myelodysplasia responsive to immunosuppressive therapy," Blood, vol. 117, no. 9, pp. 2691-2699, 2011. 
[18] A. de Hollanda, A. Beucher, D. Henrion et al., "Systemic and immune manifestations in myelodysplasia: a multicenter retrospective study," Arthritis Care and Research, vol. 63, no. 8, pp. 1188-1194, 2011.

[19] S. Giannouli, T. Kanellopoulou, and M. Voulgarelis, "Myelodysplasia and autoimmunity," Current Opinion in Rheumatology, vol. 24, no. 1, pp. 97-102, 2012.

[20] H. Enright, H. S. Jacob, G. Vercellotti, R. Howe, M. Belzer, and W. Miller, "Paraneoplastic autoimmune phenomena in patients with myelodysplastic syndromes: response to immunosuppressive therapy," British Journal of Haematology, vol. 91, no. 2, pp. 403-408, 1995.

[21] S. Giannouli, M. Voulgarelis, E. Zintzaras, A. G. Tzioufas, and H. M. Moutsopoulos, "Autoimmune phenomena in myelodysplastic syndromes: a 4-yr prospective study," Rheumatology, vol. 43, no. 5, pp. 626-632, 2004.

[22] L. A. Anderson, R. M. Pfeiffer, O. Landgren, S. Gadalla, S. I. Berndt, and E. A. Engels, "Risks of myeloid malignancies in patients with autoimmune conditions," British Journal of Cancer, vol. 100, no. 5, pp. 822-828, 2009.

[23] S. Y. Kristinsson, M. Björkholm, M. Hultcrantz, Å. R. Derolf, O. Landgren, and L. R. Goldin, "Chronic immune stimulation might act as a trigger for the development of acute myeloid leukemia or myelodysplastic syndromes," Journal of Clinical Oncology, vol. 29, no. 21, pp. 2897-2903, 2011.

[24] J. K. Mangan and S. M. Luger, "A paraneoplastic syndrome characterized by extremity swelling with associated inflammatory infiltrate heralds aggressive transformation of myelodysplastic syndromes/myeloproliferative neoplasms to acute myeloid leukemia: a case series," Case Reports in Hematology, vol. 2012, Article ID 582950, 4 pages, 2012.

[25] J. J. Frietsch, S. Dornaus, T. Neumann et al., "Paraneoplastic inflammation in myelodysplastic syndrome or bone marrow failure: case series with focus on 5-azacytidine and literature review," European Journal of Haematology, vol. 93, no. 3, pp. 247259, 2014.

[26] F. Bouali, A. Berrah, D. S. Ahmed-Bouali et al., "Immunological abnormalities in myelodysplastic syndromes. Prospective study (series of 40 patients)," Revue de Médecine Interne, vol. 26, no. 10, pp. 777-783, 2005.

[27] A. Mekinian, T. Braun, O. Decaux et al., "Inflammatory arthritis in patients with myelodysplastic syndromes: a multicenter retrospective study and literature review of 68 cases," Medicine, vol. 93, no. 1, pp. 1-10, 2014.

[28] D. R. Schneider and L. J. Picker, "Myelodysplasia in the acquired immune deficiency syndrome," American Journal of Clinical Pathology, vol. 84, no. 2, pp. 144-152, 1985.

[29] V. M. Napoli, S. F. Stein, T. J. Spira, and D. Raskin, "Myelodysplasia progressing to acute myeloblastic leukemia in an HTLV-III virus-positive homosexual man with AIDS-related complex," American Journal of Clinical Pathology, vol. 86, no. 6, pp. 788791, 1986.

[30] K. Takahashi, M. Yabe, I. Shapira, S. Pierce, G. Garcia-Manero, and M. Varma, "Clinical and cytogenetic characteristics of myelodysplastic syndrome in patients with HIV infection," Leukemia Research, vol. 36, no. 11, pp. 1376-1379, 2012.

[31] T. Ryu, M. Ikeda, Y. Okazaki et al., "Myelodysplasia associated with acquired immunodeficiency syndrome," Internal Medicine, vol. 40, no. 8, pp. 795-801, 2001.

[32] S. Rieg, M. Lübbert, W. V. Kern, S. Timme, F. Gärtner, and J.A. Rump, "Myelodysplastic syndrome with complex karyotype associated with long-term highly active antiretroviral therapy," British Journal of Haematology, vol. 145, no. 5, pp. 670-673, 2009.

[33] M. M. Oken, R. H. Creech, D. C. Tormey, J. Horton, T. E. Davis, E. T. McFadden et al., "Toxicity and response criteria of the Eastern Cooperative Oncology Group," American Journal of Clinical Oncology, vol. 5, no. 6, pp. 649-655, 1982.

[34] J. A. Savige, L. Chang, C. L. Smith, and J. C. Duggan, "Myelodysplasia, vasculitis and anti-neutrophil cytoplasm antibodies," Leukemia \& Lymphoma, vol. 9, no. 1-2, pp. 49-54, 1993.

[35] L. Zhou, A. N. Nguyen, D. Sohal et al., "Inhibition of the TGFbeta receptor I kinase promotes hematopoiesis in MDS," Blood, vol. 112, no. 8, pp. 3434-3443, 2008.

[36] J. Maciejewski, C. Selleri, S. Anderson, and N. S. Young, "Fas antigen expression on CD34+ human marrow cells is induced by interferon gamma and tumor necrosis factor alpha and potentiates cytokine-mediated hematopoietic suppression in vitro," Blood, vol. 85, no. 11, pp. 3183-3190, 1995.

[37] D. L. Stirewalt, A. J. Mhyre, M. Marcondes et al., "Tumour necrosis factor-induced gene expression in human marrow stroma: clues to the pathophysiology of MDS?" British Journal of Haematology, vol. 140, no. 4, pp. 444-453, 2008.

[38] C. L. Willman, C. E. Sever, M. G. Pallavicini et al., "Deletion of IRF-1, mapping to chromosome 5q31.1, in human leukemia and preleukemic myelodysplasia," Science, vol. 259, no. 5097, pp. 968-971, 1993.

[39] H. Harada, T. Kondo, S. Ogawa et al., "Accelerated exon skipping of IRF-1 mRNA in human myelodysplasia/leukemia; a possible mechanism of tumor suppressor inactivation," Oncogene, vol. 9, no. 11, pp. 3313-3320, 1994.

[40] T. Braun and P. Fenaux, "Myelodysplastic Syndromes (MDS) and autoimmune disorders (AD): cause or consequence?" Best Practice and Research: Clinical Haematology, vol. 26, no. 4, pp. 327-336, 2013.

[41] S. Y. Kordasti, W. Ingram, J. Hayden et al., "CD $4^{+} \mathrm{CD} 25^{\text {high }}$ Foxp $3^{+}$regulatory T cells in myelodysplastic syndrome (MDS)," Blood, vol. 110, no. 3, pp. 847-850, 2007.

[42] I. Kotsianidis, I. Bouchliou, E. Nakou et al., "Kinetics, function and bone marrow trafficking of $\mathrm{CD} 4{ }^{+} \mathrm{CD} 25^{+} \mathrm{FOXP} 3^{+}$regulatory T cells in myelodysplastic syndromes (MDS)," Leukemia, vol. 23, no. 3, pp. 510-518, 2009.

[43] A. Sternberg, S. Killick, T. Littlewood et al., "Evidence for reduced B-cell progenitors in early (low-risk) myelodysplastic syndrome," Blood, vol. 106, no. 9, pp. 2982-2991, 2005.

[44] J.-J. Kiladjian, E. Bourgeois, I. Lobe et al., "Cytolytic function and survival of natural killer cells are severely altered in myelodysplastic syndromes," Leukemia, vol. 20, no. 3, pp. 463470, 2006.

[45] P. K. Epling-Burnette, F. Bai, J. S. Painter et al., "Reduced natural killer (NK) function associated with high-risk myelodysplastic syndrome (MDS) and reduced expression of activating NK receptors," Blood, vol. 109, no. 11, pp. 4816-4824, 2007.

[46] A. W. Mailloux, C. Sugimori, R. S. Komrokji et al., "Expansion of effector memory regulatory $\mathrm{T}$ cells represents a novel prognostic factor in lower risk myelodysplastic syndrome," The Journal of Immunology, vol. 189, no. 6, pp. 3198-3208, 2012.

[47] D. Watanabe, T. Uehira, H. Yonemoto et al., "Sustained high levels of serum interferon- $\gamma$ during HIV-1 Infection: a specific trend different from other cytokines," Viral Immunology, vol. 23, no. 6, pp. 619-625, 2010. 
[48] D. Trabattoni, S. Fossati, M. Biasin et al., "Functional analysis of HIV-specific cytotoxic T lymphocytes in antiviral-treatedand-naive patients: a preliminary report," Journal of Biological Regulators and Homeostatic Agents, vol. 16, no. 1, pp. 25-29, 2002.

[49] P. C. Mutevedzi, A. J. Rodger, P. Kowal, M. Nyirenda, and M.-L. Newell, "Decreased chronic morbidity but elevated HIV associated cytokine levels in HIV-infected older adults receiving HIV treatment: benefit of enhanced access to care?" PLoS ONE, vol. 8, no. 10, Article ID e77379, 2013.

[50] A. Lim, D. Tan, P. Price et al., "Proportions of circulating T cells with a regulatory cell phenotype increase with HIV-associated immune activation and remain high on antiretroviral therapy," AIDS, vol. 21, no. 12, pp. 1525-1534, 2007.

[51] S. D. Douglas, S. J. Durako, N. B. Tustin, J. Houser, L. Muenz, and S. E. Starr, "Natural killer cell enumeration and function in HIV-infected and high-risk uninfected adolescents," AIDS Research and Human Retroviruses, vol. 17, no. 6, pp. 543-552, 2001.

[52] P. T. Diamantopoulos, M. Michael, O. Benopoulou et al., "Antiretroviral activity of 5-azacytidine during treatment of a HTLV-1 positive myelodysplastic syndrome with autoimmune manifestations," Virology Journal, vol. 9, article 1, 2012.

[53] C. Fernández-Miranda, A. García-Marcilla, M. Martín et al., "Vasculitis associated with a myelodysplastic syndrome: a report of 5 cases," Medicina Clinica, vol. 103, no. 14, pp. 539-542, 1994.

[54] S. W. George and E. D. Newman, "Seronegative inflammatory arthritis in the myelodysplastic syndromes," Seminars in Arthritis \& Rheumatism, vol. 21, no. 6, pp. 345-354, 1992.

[55] H. Enright and W. Miller, "Autoimmune phenomena in patients with myelodysplastic syndromes," Leukemia \& Lymphoma, vol. 24, no. 5-6, pp. 483-489, 1997.

[56] S. Aggarwal, A. A. van de Loosdrecht, C. Alhan, G. J. Ossenkoppele, T. M. Westers, and H. J. Bontkes, "Role of immune responses in the pathogenesis of low-risk MDS and highrisk MDS: implications for immunotherapy," British Journal of Haematology, vol. 153, no. 5, pp. 568-581, 2011.

[57] L. A. Godley and R. A. Larson, "Therapy-related myeloid leukemia," Seminars in Oncology, vol. 35, no. 4, pp. 418-429, 2008.

[58] J. Zhou, C.-Y. Wang, T. Liu et al., "Persistence of side population cells with high drug efflux capacity in pancreatic cancer," World Journal of Gastroenterology, vol. 14, no. 6, pp. 925-930, 2008.

[59] M. Bower, N. McCall-Peat, N. Ryan et al., "Protease inhibitors potentiate chemotherapy-induced neutropenia," Blood, vol. 104, no. 9, pp. 2943-2946, 2004.

[60] C. Chelucci, H. J. Hassan, C. Locardi et al., "In vitro human immunodeficiency virus-1 infection of purified hematopoietic progenitors in single-cell culture," Blood, vol. 85, no. 5, pp. 11811187, 1995.

[61] A. V. Moses, S. Williams, M. L. Heneveld et al., "Human immunodeficiency virus infection of bone marrow endothelium reduces induction of stromal hematopoietic growth factors," Blood, vol. 87, no. 3, pp. 919-925, 1996.

[62] C. L. Clouser, C. M. Holtz, M. Mullett et al., "Activity of a novel combined antiretroviral therapy of gemcitabine and decitabine in a mouse model for HIV-1," Antimicrobial Agents and Chemotherapy, vol. 56, no. 4, pp. 1942-1948, 2012.

[63] M. J. Dapp, C. M. Holtz, and L. M. Mansky, "Concomitant lethal mutagenesis of human immunodeficiency virus type 1," Journal of Molecular Biology, vol. 419, no. 3-4, pp. 158-170, 2012.
[64] J. Bouchard, M. C. Walker, J.-M. Leclerc, N. Lapointe, R. Beaulieu, and L. Thibodeau, "5-Azacytidine and 5-azadeoxycytidine inhibit human immunodeficiency virus type 1 replication in vitro," Antimicrobial Agents and Chemotherapy, vol. 34, no. 2, pp. 206-209, 1990.

[65] E. Vaccher, M. Spina, G. di Gennaro et al., "Concomitant cyclophosphamide, doxorubicin, vincristine, and prednisone chemotherapy plus highly active antiretroviral therapy in patients with human immunodeficiency virus-related, nonHodgkin lymphoma," Cancer, vol. 91, no. 1, pp. 155-163, 2001.

[66] H. Ezzat, D. Filipenko, L. Vickars et al., "Improved survival in HIV-associated diffuse large B-cell lymphoma with the addition of rituximab to chemotherapy in patients receiving highly active antiretroviral therapy," HIV Clinical Trials, vol. 8, no. 3, pp. 132144, 2007.

[67] J. A. Rodrigo, L. K. Hicks, M. C. Cheung et al., "HIV-associated Burkitt lymphoma: good efficacy and tolerance of intensive chemotherapy including CODOX-M/IVAC with or without rituximab in the HAART era," Advances in Hematology, vol. 2012, Article ID 735392, 9 pages, 2012.

[68] J.-T. Navarro, N. Lloveras, J.-M. Ribera, A. Oriol, J.-L. Mate, and E. Feliu, "The prognosis of HIV-infected patients with diffuse large B-cell lymphoma treated with chemotherapy and highly active antiretroviral therapy is similar to that of HIV-negative patients receiving chemotherapy," Haematologica, vol. 90, no. 5, pp. 704-706, 2005.

[69] R. A. Wells, B. Leber, N. Y. Zhu, and J. M. Storring, "Optimizing outcomes with azacitidine: recommendations from Canadian centres of excellence," Current Oncology, vol. 21, no. 1, pp. 44-50, 2014.

[70] M. Breccia, G. Gentile, P. Martino et al., "Acute myeloid leukemia secondary to a myelodysplastic syndrome with $\mathrm{t}(3 ; 3)$ (q21;q26) in an HIV patient treated with chemotherapy and highly active antiretroviral therapy," Acta Haematologica, vol. 111, no. 3, pp. 160-162, 2004.

[71] L. Sutton, P. Guénel, M.-L. Tanguy et al., "Acute myeloid leukaemia in human immunodeficiency virus-infected adults: epidemiology, treatment feasibility and outcome," British Journal of Haematology, vol. 112, no. 4, pp. 900-908, 2001. 


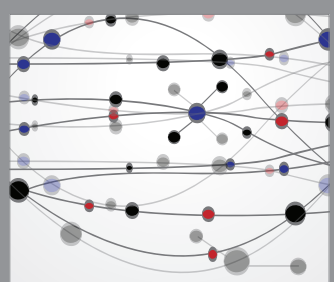

The Scientific World Journal
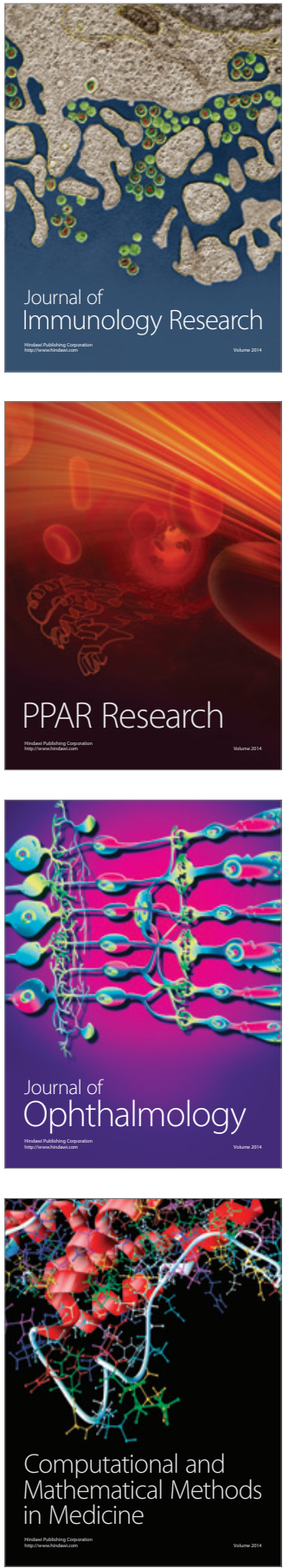

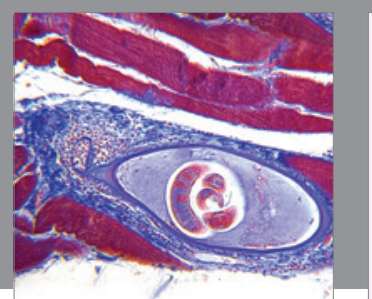

Gastroenterology Research and Practice

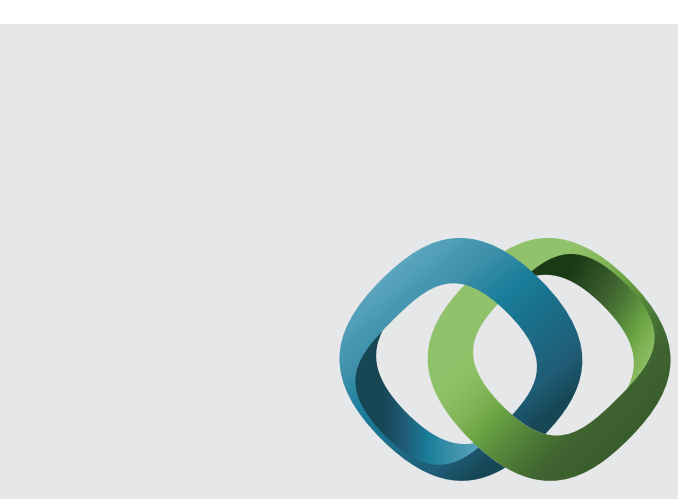

\section{Hindawi}

Submit your manuscripts at

http://www.hindawi.com
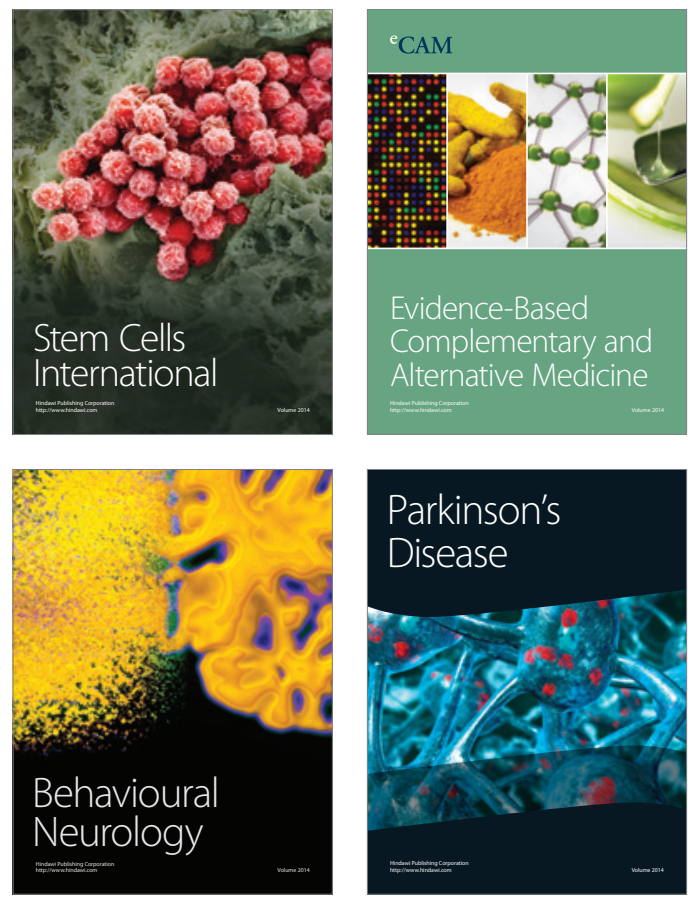
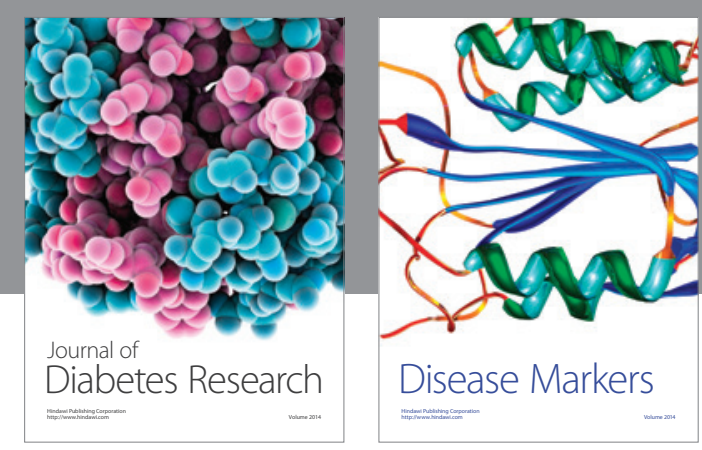

Disease Markers
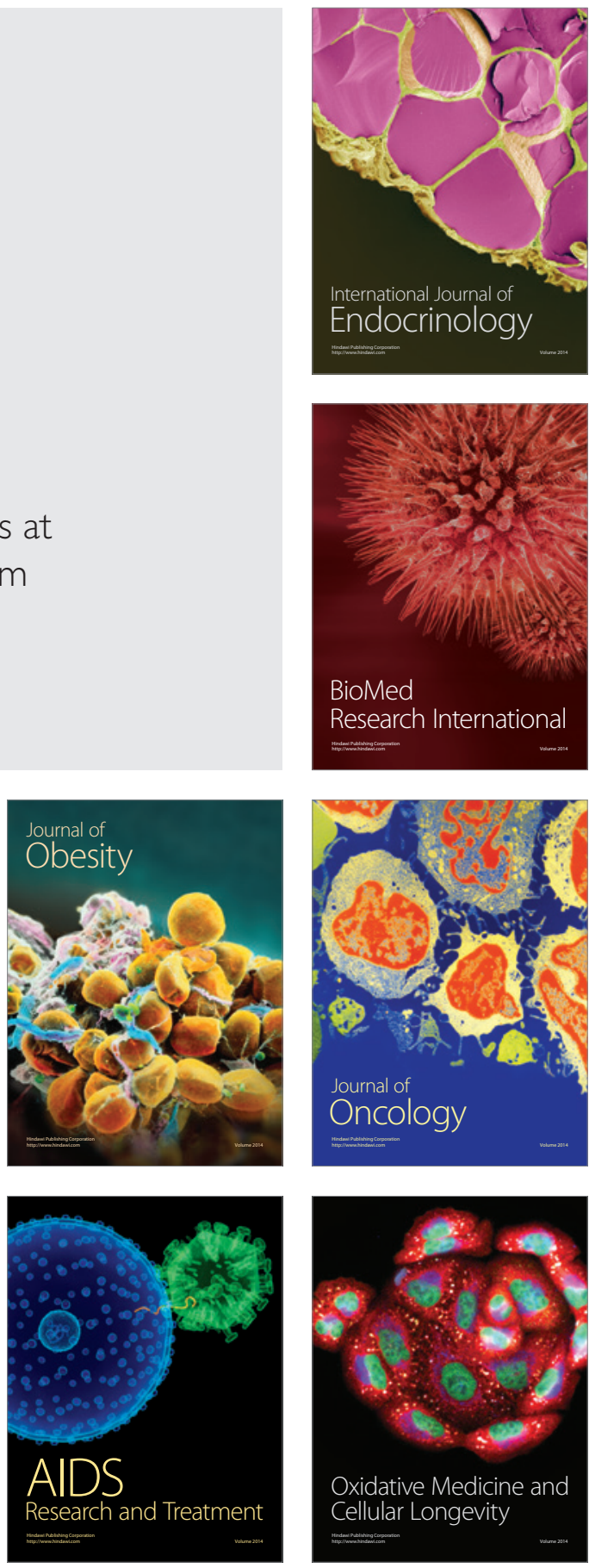